УДК 634.8: 632.4: 575.174.015.3

DOI 10.30679/2219-5335-2021-1-67-294-304

ИЗУЧЕНИЕ ПОЛИМОРФИЗМА

ПОПУЛЯЦИИ PLASMOPARA VITICOLA

В РАЗНЫЕ ГЕНЕРАЦИИ ПАТОГЕНА*

Кожевников Евгений Анатольевич

студент кафедры биологии

и экологии растений

e-mail: zhenya.kozhevnikov.2017@bk.ru

Федеральное государственное

бюджетное образовательное

учреждение выстего образования

«Кубанский государственный

университет»,

Краснодар, Россия

Макаркина Марина Викторовна

младший научный сотрудник

лаборатории сортоизучения

и селекции винограда

e-mail: konec_citatu@mail.ru

Ильницкая Елена Тарасовна

канд. биол. наук

зав. лабораторией сортоизучения

и селекции винограда

e-mail: ilnitskaya79@mail.ru

Федеральное государственное

бюджетное научное учреждение

«Северо-Кавказский федеральный

научный центр садоводства,

виноградарства, виноделия»,

Краснодар, Россия

Милдью - заболевание виноградной лозы, вызываемое облигатным

гетероталличным биотрофным эндопаразитом Plasmopara viticola. Ареалом распространения данного патогена являются виноградники
UDC 634.8: 632.4: 575.174.015.3

DOI 10.30679/2219-5335-2021-1-67-294-304

\section{STUDY OF PLASMOPARA VITICOLA POPULATION POLYMORPHISM IN DIFFERENT PATHOGEN GENERATIONS*}

Kozhevnikov Evgeniy Anatolievich Student of the Department of Plant Biology and Ecology e-mail: zhenya.kozhevnikov.2017@bk.ru

Federal State Budgetary

Educational Institution

of Higher Professional

Education «Kuban State

University»,

Krasnodar, Russia

Makarkina Marina Victorovna

Junior Research Associate

of Laboratory of Cultivar's Study

and Breeding of Grapes

e-mail: konec_citatu@mail.ru

Ilnitskaya Elena Tarasovna

Cand. Biol. Sci.

Head of Laboratory of Cultivar's study

and Breeding of Grapes

e-mail: ilnitskaya79@mail.ru

Federal State Scientific

Budget Institution

"North-Caucasian Federal

Scientific Center of Horticulture,

Viticulture, Winemaking»,

Krasnodar, Russia

Downy mildew is a vine disease caused by the obligate heterothallic biotrophic endoparasite Plasmopara viticola.

The area of distribution of this pathogen are vineyards all over the world,

\footnotetext{
* Исследование выполнено при финансовой поддержке РФФИ и Администрации Краснодарского края в рамках научного проекта № 19-416-233038 р_мол_а.

* The study was carried out with financial support from the Russian Foundation for Basic Research and the Administration of the Krasnodar Territory, project No. 19-416-233038 r m mol a.
} 
всего мира, но наибольшие потери несут зоны виноградарства с умеренноконтинентальным и субтропическим климатом. В Краснодарском крае эпифитотийное развитее милдью бывает 6-7 раз за 10 лет. Первые молекулярногенетические исследования патогена были начаты ещё в конце XX века. Цель данной работы - оценить на основе ДНК-маркерного анализа полиморфизм популяции $P$. viticola в двух генерациях патогена на виноградных растениях, произрастающих в изолированной географической точке. Материалом для исследования послужили пораженные листья винограда, собранные на вегетационной площадке ФГБНУ СКФНЦСВВ с растений, не подвергавшихся химическим обработкам. Сбор материала осуществляли в двух временных интервалах - конец июля (первая генерация патогена 4 образца) и середина августа (вторая генерация -6 образцов). Для изучения разнообразия использовали высокополиморфные SSR-маркеры GOB и PV144. ДНК P. viticola выделяли непосредственно из инфицированных листьев ЦТАБ-методом. Всего было проанализировано 10 образцов ДНК патогена. Исследование выполнено классическим методом полимеразной цепной реакции. Размер целевых фрагментов локусов PV144 и GOB оценивали при помощи автоматического генетического анализатора ABI Prism 3130 методом фрагментного анализа. Полученные данные анализировали в программе Gene Mapper 4.1. Наибольшая степень полиморфизма была обнаружена по маркеру GOB - 7 типов аллелей, в меньшей степени PV144 - 4 типа аллелей. Было установлено, что образцы популяция патогена, собранные в период первой генерации, обладают значительно большим генетическим полиморфизмом в отличие от образцов, собранных в период второй генерации. Исследования в данном направлении продолжаются.

Ключевые слова: ВИНОГРАД, МИЛДЬЮ, PLASMOPARA VITICOLA, ГЕНЕРАЦИИ ПАТОГЕНА, ГЕНЕТИЧЕСКОЕ РАЗНООБРАЗИЕ, ДНК-МАРКЕРЫ but the greatest losses are in the viticulture zones with a temperate continental and subtropical climate. In Krasnodar Territory, epiphytotic development of mildew occurs 6-7 times in 10 years. The first molecular genetic studies of the pathogen began at the end of the 20th century. The purpose of this work is to evaluate, based on DNA marker analysis, the polymorphism of the $P$. viticola population in two generations of the pathogen on grape plants growing in an isolated geographic point. The material for the study was the affected grape leaves taken from the vegetation plot of the FSBSI NCFSCHVW, from plants without chemical treatment. The material was taken in two time intervals - the end of July (the first generation of the pathogen -4 samples) and the middle of August (the second generation -6 samples). To study the diversity, highly polymorphic SSR-markers - GOB and PV144, were used. $P$. viticola DNA was isolated directly from infected leaves by the CTAB method. A total of 10 DNA samples of the pathogen were analyzed. The study was carried out by the classical method of polymerase chain reaction. The size of the target fragments of the PV144 and GOB loci was estimated using an ABI Prism 3130 automatic genetic analyzer by fragment analysis. The data obtained were analyzed using Gene Mapper 4.1 software. The highest degree of polymorphism was found for the GOB marker - 7 types of alleles and to a lesser extent PV144 - 4 types of alleles.

It was found that the samples of the pathogen population collected during the first generation have significantly higher genetic polymorphism, in contrast to the samples collected during the second generation. Research in this direction continues.

Key words: GRAPEVINE, DOWNY MILDEW, PLASMOPARA VITICOLA, PATHOGEN GENERATIONS, GENETIC DIVERSITY, DNA MARKERS 
Введение. Милдью - одно из наиболее опасных заболеваний европейских сортов винограда, вызываемое облигатным биотрофным гетероталличным микромицетом Plasmopara viticola Berl. Et de Toni, пренадлежащему к классу Oomycota порядку Peronospora. Патоген является эндемиком юговостока Северной Америки, откуда и был завезен на территорию Европы вместе с посадочным материалом [1-3].

Болезнь поражает все зеленые органы растения, в особенности листья и ягоды. Наибольшая интенсивность развития и распространения патогена наблюдается при влажной и теплой погоде в период с мая до поздней осени. Зимует гриб в опавшей листве в виде ооспор (макроконидий), которые при повышении влажности и температурного режима прорастают, образуя зооспорангии (микроконидии). Последние вместе с потоками воздуха, каплями воды, росой попадают на вентральную часть листа, где высвобождают зооспоры. Подвижные зооспоры через устьица проникают в ткани растения, вызывая первичное заражение [4].

По мере развития патогена на дорсальной стороне листовой пластинки появляются морфологические симптомы развития болезни: желтоватые или хлоротичные пятна различного диаметра. Примерно по истечении 24 часов после первичного заражения, в благоприятных условиях, на вентральной стороне листа появляется мучнистый налет - конидиеносцы с конидиями. Максимальная длина конидиеносцев достигает 1 мм. Зрелые конидиеносцы с конидиями могут стать причиной вторичной инфекции и вызвать более серьезные последствия, попав на молодые соцветия или ягоды.

Повторное заражение растений происходит аналогичным образом, только в качестве первоисточника выступает не зимующая ооспора, а зооспорангии, образовавшиеся в ходе первичного заражения. В благоприятный для развития милдью год может наблюдаться от 7-8 и более генераций. Вирулентность зооспор каждой из генераций зависит как от погодных условий, так и от растения-хозяина [5] 
Микромицет размножается преимущественно бесполым способом при помощи зооспор. Переход к половому размножению наблюдается только в случае наступления неблагоприятных условий для бесполого. Образующиеся в результате полового размножения ооспоры способны сохранять жизнеспособность в течение длительного времени - от шести до восьми лет [6].

На сегодняшний день систематическое положение возбудителя милдью определено. Но так было не всегда. После обнаружения патогена вопрос о его классификации оставался дискуссионным более полувека. В 1834 году Швайниц классифицировал гриб как Botrytis cana Link. Позднее в 1855 году Берклей и Куртис, изучая образцы, собранные в 1848 с инфицированного винограда, отнесли его к виду Botrytis viticola. В 1863 году А. де Бари, подробнее изучая биологию патогена, отнес его к роду Peronospora, под видовым названием Peronospora viticola. Некоторое время спустя, по предложению Шрётера, из рода Peronospora в новый самостоятельный род был выделен целый ряд грибов, отнесенный им к Plasmopara. И только в 1888 году Берлез и де Тони классифицировали возбудителя милдью как Plasmopara viticola [7].

К изучению генетических особенностей $P$. viticola исследователей косвенно подтолкнуло развитие химической промышленности, в частности увеличение числа разнообразных фунгицидов. Активное применение фунгицидов против возбудителя милдью повлияло на его геном, трансформируя его в сторону повышения резистентности к применяемым препаратам $[8,9]$. Для того чтобы объяснить стремительное развитие резистентности P. viticola к применяемым фунгицидам, были начаты изучения генетической структуры патогена.

В настоящее время для идентификации живых организмов, а также детекции различий между ними исследователи используют молекулярно-генетические методы. Первыми маркерами, применяемыми в изучении генетической структуры популяции P. Viticola, были маркеры типа RAPD (random amplified polymorphic DNA) [10, 11]. Исследования, базирующиеся 
Плодоводство и виноградарство Юга России № 67(1), 2021 г.

на применении маркеров данного типа, не требуют предварительных знаний нуклеотидной последовательности участков ДНК организма. Однако RAPD-маркеры, в силу своей структуры, не гарантирует амплификацию целевых областей ДНК, что конечно же является их минусом.

Проведение популяционно-генетических исследований данного эндопаразита требовало разработки специфичных и кодоминантных маркеров. В 2003 году D. Gobbin и соавторы разработали SSR-маркеры (Simple Sequence Repeats) - BER, ISA, CES, REX, GOB, которые соответствуют вышеприведенным требованиям. На сегодняшний день известно 11 SSR и 8 SNP-маркеров, но поиск и разработка новых ДНК-маркеров для изучения P. viticola продолжаются [12-16]

Цель работы - изучить разнообразие популяции $P$. viticola в разные генерации патогена на виноградных растениях, произрастающих в одной изолированной географической точке, при помощи высокополиморфных микросателлитных ДНК-маркеров GOB и PV144.

Объекты и методы исследований. Для изучения полиморфизма возбудителя ложной мучнистой росы виноградной лозы нами использовались ДНК маркеры GOB и PV144, рекомендованные для изучения популяции P. viticola $[13,15]$. Материалом выступали образцы (пораженные милдью листья винограда), собранные на вегетационной площадке СКФНЦССВ (г. Краснодар), где растения не подвергались обработке фунгицидами. Сбор материала осуществлялся в двух временных интервалах - конец июля (первая генерация - 4 образца) и середина августа (вторая генерация - 6 образцов). ДНК P. viticola выделяли непосредственно из инфицированных листьев ЦТАБ-методом [17]. Всего было экстрагировано 10 образцов ДНК.

Исследование выполнено классическим методом ПЦР при помощи амплификатора «BioRad» согласно следующей схеме: 3 минуты при $95^{\text {o }}$ начальная денатурация, затем 35 циклов: 20 секунд при $95^{\circ}$ - денатурация, 30 секунд - отжиг праймеров GOB при $60^{\circ} \mathrm{C}, \mathrm{PV} 144$ - при $58^{\circ} \mathrm{C} ; 40$ секунд 
при $72^{\circ} \mathrm{C}$ - элонгация; затем 5 минут при $72^{\circ} \mathrm{C}-$ финальная элонгация, отработанная нами в предыдущих исследованиях $[18,19]$.

В ПЦР смесь объемом 25 мкл входили следующие компоненты: 50-70 нг ДНК, 1х ПЦР буфер для Таq-полимеразы с сульфатом аммония и магнием, 0,125 мМ/мкл dNTP, 0,25 пМ/мкл каждого праймера, 0,05 \% БСА (бычий сывороточный альбумин), 0,125 ед./мкл Таq-полимеразы. БСА добавлен в смесь в качестве антагониста, ингибирующего действие полифенолов, способных влиять на качество прохождения полимеразной цепной реакции. Размер ампликонов оценивали на автоматическом генетическом анализаторе ABI Prism 3130 (USA) методом фрагментного анализа. Полученные результаты анализировали в программе Gene Mapper 4.1.

Обсужжение результатов. Задачей данного исследования являлось изучение степени полиморфизма возбудителя ложной мучнистой росы при помощи наиболее полиморфных маркеров GOB и PV144 в относительно небольшой выборке (10 образцов). Маркер GOB оказался наиболее полиморфным (выявлено 7 типов аллелей: 273, 277, 292, 294, 300, 304, 369), в меньшей степени был полиморфен PV144 (4 типа аллелей: 176, 185, 189, 192).

По данным, приведенным в таблице, можно сделать вывод о том, что материал, собранный в период первой генерации, обладает значительно большим полиморфизмом, в отличии от материала, собранного в период второй генерации. Трансформация генетической структуры популяции патогена, возможно, свидетельствует об адаптивных механизмах в ответ на неблагоприятные климатические условия и специфику генетики и физиологии растения-хозяина, что привело к размножению и превалированию в популяции патогена одного генотипа.

Образцы патогена были собраны на гибридных формах винограда, полученных от скрещивания сорта винограда Мицар (Серексия х Каберне Совиньон) и элитной формы TAHA74 (Seyve Villard 12-309 х Мускат кубанский), имеющих в своей родословной потенциальный донор устойчивости к 
милдью - SV 12-309. Результаты исследования образцов с этих же растений (2-я генерация) показали стабилизацию структуры популяции патогена: видно, что все образцы из второй генерации идентичны по анализируемым локусам (табл.).

Результаты ПЦР-анализа

\begin{tabular}{|c|c|c|c|}
\hline \multirow{2}{*}{$\begin{array}{c}\text { Генерация } \\
\text { патогена }\end{array}$} & \multirow{2}{*}{ Образец } & \multicolumn{2}{|c|}{ Идентифицированные аллели, п. н. } \\
\cline { 2 - 4 } & 1 & GOB & PV144 \\
\hline \multirow{4}{*}{1} & 2 & $292: 300$ & $176: 189$ \\
\cline { 2 - 4 } & 3 & $294: 304$ & $176: 192$ \\
\cline { 2 - 4 } & 4 & $294: 369$ & $176: 185$ \\
\hline \multirow{4}{*}{2} & 5 & $277: 277$ & $176: 176$ \\
\cline { 2 - 4 } & 6 & $273: 294$ & $176: 185$ \\
\cline { 2 - 4 } & 7 & $273: 294$ & $176: 185$ \\
\cline { 2 - 4 } & 8 & $273: 294$ & $176: 185$ \\
\cline { 2 - 4 } & 9 & $273: 294$ & $176: 185$ \\
\cline { 2 - 4 } & 10 & $273: 294$ & $176: 185$ \\
\hline
\end{tabular}

Следует отметить, что участок, на котором производился сбор материала двух генераций, не обрабатывался фунгицидами, являющимися одним из основных экзогенных факторов возникновения изменений в структуре популяции патогена. Однако результаты анализа первой и второй генерации говорят о том, что преобразования генетического материала могут наблюдаться не только вследствие обработки растений химическими веществами, но и зависят от других экзогенных и эндогенных факторов.

Полученные результаты сопоставимы с мировыми исследования генетической структуры популяции $P$. viticola в различные генерации патогена. Так, в 2005 году Gobbin et al., чтобы количественно оценить величину и пространственное распространение вторичных спорангий милдью виноградной лозы, изучил 4685 образцов Plasmopara viticola, собранных по всей Центральной Европе [20]. Было показало, что эпидемия милдью является результатом взаимодействия множества генотипов, каждый из которых вызы- 
вает ограниченное поражение (или несколько), и есть доминирующий генотип, способный распространяться поэтапно на всем масштабе участка. В нашем случае доминирующим генотипом, по данным ДНК-анализа, оказалась популяция, содержащая аллели 176 п.н. и 294 п.н. по маркерам PV144 и GOB, соответственно, так как данные аллели выявлялись как в первой, так и во второй генерации патогена (рис. 1, рис. 2).

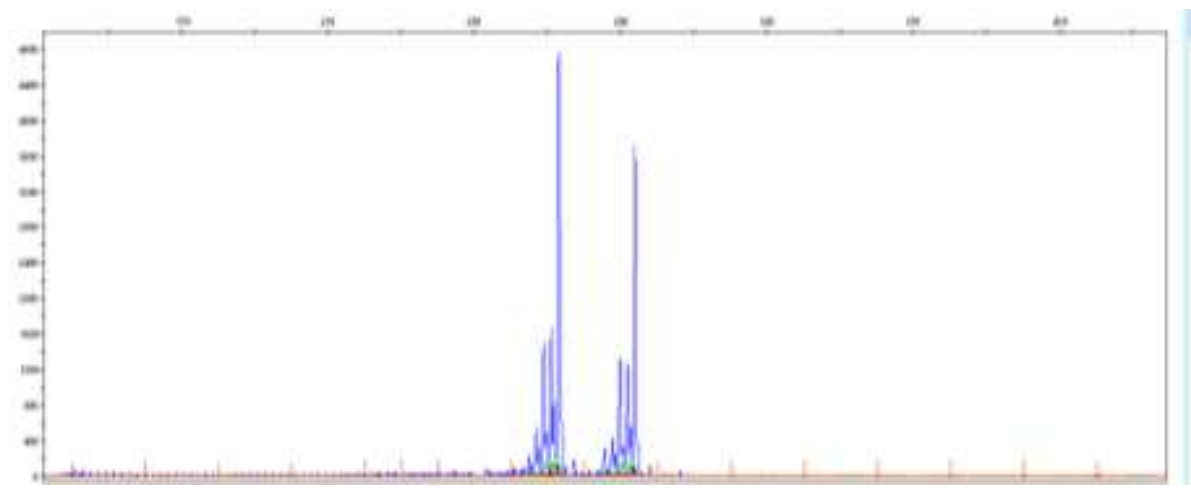

Рис. 1. Результаты фрагментного анализа с маркером GOB образца ДНК из второй генерации патогена (аллели 273:294)

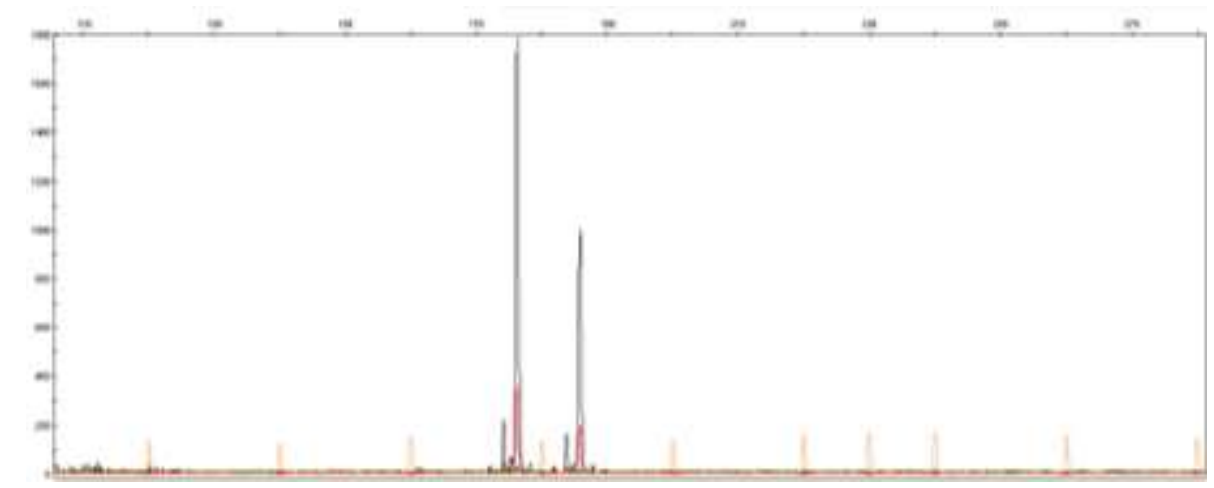

Рис. 2. Результаты фрагментного анализа с маркером PV144 образца ДНК из второй генерации патогена (аллели 176:185)

Интересно, что при изучении второй генерации выявлена аллель 273 п.н. маркером GOB, которая не была выявлена при изучении образцов первой генерации. Однако следует отметить, что исследуемая выборка была небольшая, и также возможно, что генотип патогена с данной аллелью находился в малом количестве и подавлялся другими генотипами в 
Плодоводство и виноградарство Юга России № 67(1), 2021 г.

первую генерацию. До конца не понятны все причины, связанные с подобными изменениями в структуре популяции патогена, но однозначно известно, что климатические условия и обработка химикатами имеют весомое место в этом процессе. Генотип растения-хозяина, вероятно, также может вносить коррективы в структуру популяции патогена. Исследования в этом направлении продолжаются.

Заключение. С помощью высокополиморфных микросателлитных ДНК-маркеров GOB и PV144 изучено разнообразие популяции P. viticola на растениях винограда, произрастающих на вегетационной площадке ФГБНУ СКФНЦСВВ. ДНК-маркеры GOB и PV144 выявили достаточно высокий полиморфизм в относительно небольшой выборке исследуемых образцов -7 и 4 типов аллелей, соответственно. На конкретном примере показаны изменения структуры популяции возбудителя милдью в одной географической точке в различные генерации патогена. В дальнейших исследованиях планируется увеличить выборку и географию сбора образцов, чтобы попытаться сделать выводы о факторах, влияющих на изменение генетической структуры популяции $P$. viticola.

\section{Литература}

1. Wong F.P., Wilcox W.F. Distribution of baseline sensitivities to azoxystrobin among isolates of Plasmopara viticola // Plant Disease. 2000. Vol. 84. P. 275-281.

2. Вердеревский Д. Д., Войтович К. А. Милдью винограда. Кишинев: Картя Молдовеняскэ, 1970. 69 с.

3. Fontaine M. C., Labbe F., Dussert Y., Deliere L., Richart-Cervera S., Giraud T., Delmotte F. Europe as a bridgehead in the worldwide invasion history of grapevine downy mildew, Plasmopara viticola // BioRxiv. 2020.

4. Salinari F., Giosuè S., Tubiello F., Rettori A., Rossi V., Spanna, F., Gullino M.L. Downy mildew (Plasmopara viticola) epidemics on grapevine under change. 2006. P. 1299-1307.

5. Стороженко Е.М. Болезни плодовых культур и винограда. Краснодар, 1970. C. $128-188$.

6. Волкова А.А. Грибные болезни винограда и агроприемы в борьбе с ними [Электронный ресурс] // Плодоводство и виноградарство Юга России. 2010. № 4(3). С. 86-90. URL: http://journalkubansad.ru/pdf/10/03/13.pdf. (дата обращения: 14.01.2021).

7. Gessler C., Pertot I., Perazzolli M. Plasmopara viticola: a review of knowledge on downy mildew of grapevine and effective disease management // Phytopathologia Mediterranea. 2011. Vol. 50(1). P. 3-44. 
8. Toffolatti S. L., Prandato M., Serrati L., Sierotzki H., Gisi U., Vercesi A. Evolution of Qol resistance in Plasmopara viticola oospores // European journal of plant pathology. 2011. V. 129(2). P. 331-338.

9. Santos R. F., Ciampi-Guillardi M., Fraaije B. A., de Oliveira A. A., Amorim L. The Climate-Driven Genetic Diversity Has a Higher Impact on the Population Structure of Plasmopara viticola Than the Production System or QoI Fungicide Sensitivity in Subtropical Brazil // Frontiers in microbiology. 2020. V. 11. P. 2236.

10. Kump I., Gessler C., Blaise P. Primary infections of Plasmopara viticola: should we revise our ideas about the quantitative relevance of oospores? // Bulletin OILB/SROP. 1998. Vol. 21(2). P. 9-11.

11. Stark-Urnau M., Seidel M., Kast W., Gemmrich A. Studies on the genetic diversity of primary and secondary infections of Plasmopara viticola using RAPD/PCR // Vitis. 2000. Vol. 39 (4). P. 163-166.

12. Delmotte F., Chen W. J., Richard-Cervera S., Greif C., Papura D., Giresse X., MondorGenson G., Corio-Costet M. F. Microsatellite DNA markers for Plasmopara viticola, the causal agent of downy mildew of grapes // Molecular Ecology Notes. 2006. Vol. 6 (2). P. 379-381.

13. Gobbin D., Pertot I., Gessler C. Identification of microsatellite markers for Plasmopara viticola and establishment of high throughput method for SSR analysis // European journal of plant pathology. 2003. Vol. 109 (2). P. 153-164.

14. Delmotte F., Machefer V., Giresse X., Rc S., Latorse M., Beffa R. Characterization of single-nucleotide-polymorphism markers for Plasmopara viticola, the causal agent of grapevine downy mildew // Applied and environmental microbiology. 2011. Vol. 77 (21). P. 7861-7863.

15. Rouxel M., Papura D., Nogueira M., Machefer V., Dezette D., Rc S., Carrere S., Mestre P., Delmotte F. Microsatellite markers for characterization of native and introduced populations of Plasmopara viticola, the causal agent of grapevine downy mildew // Applied and environmental microbiology. 2012. Vol. 78 (17). P. 6337-6340.

16. Arafa R., Kenta S. Technical review of molecular markers and next-generation sequencing technology to manage plant pathogenic oomycetes // African journal of biotechnology. 2018. Vol. 17 (12). P. 369-379.

17. Rogers S.O., Bendich A.J. Extraction of DNA from milligram amounts of fresh, herbarium and mummified plant tissues // Plant Molecular Biology. 1985. Vol. 5(2). P. 69-76.

18. Макаркина М.В., Ильницкая Е.Т., Токмаков С.В., Лободина Е.В. Апробация днк-маркеров для изучения разнообразия патогена Plasmopara Viticola [Электронный ресурс] // Плодоводство и виноградарство Юга России. 2019. № 60(6). C. 41-50. URL: http://journalkubansad.ru/pdf/19/06/05.pdf. DOI: 10.30679/2219-5335-2019-6-60-41-50 (дата обращения: 14.01.2021).

19. Makarkina M. V., Tokmakov S. V., Ilnitskaya E. T. A study of the genetic polymorphism of Plasmopara viticola in the vineyards of the Krasnodar Territory // BIO Web of Conferences. II International scientific conference "plants and microbes: the future of biotechnology". 2020. Vol. 23. P. 02005.

20. Gobbin D., Jermini M., Loskill B., Pertot I., Raynal M., Gessler C. Importance of secondary inoculum of Plasmopara viticola to epidemics of grapevine downy mildew // Plant Pathology. 2005. Vol. 54. P. 522-534.

\section{References}

1. Wong F.P., Wilcox W.F. Distribution of baseline sensitivities to azoxystrobin among isolates of Plasmopara viticola // Plant Disease. 2000. Vol. 84. P. 275-281.

2. Verderevskij D. D., Vojtovich K. A. Mild'yu vinograda. Kishinev: Kartya Moldovenyaske, 1970. $69 \mathrm{~s}$.

3. Fontaine M. C., Labbe F., Dussert Y., Deliere L., Richart-Cervera S., Giraud T., Delmotte F. Europe as a bridgehead in the worldwide invasion history of grapevine downy mildew, Plasmopara viticola // BioRxiv. 2020. 
4. Salinari F., Giosuè S., Tubiello F., Rettori A., Rossi V., Spanna, F., Gullino M.L. Downy mildew (Plasmopara viticola) epidemics on grapevine under change. 2006. P. 1299-1307.

5. Storozhenko E.M. Bolezni plodovyh kul'tur i vinograda. Krasnodar, 1970. S. 128-188.

6. Volkova A.A. Gribnye bolezni vinograda i agropriemy v bor'be s nimi [Elektronnyj resurs] // Plodovodstvo i vinogradarstvo Yuga Rossii. 2010. № 4(3). S. 86-90. URL: http://journalkubansad.ru/pdf/10/03/13.pdf. (data obrashcheniya: 14.01.2021).

7. Gessler C., Pertot I., Perazzolli M. Plasmopara viticola: a review of knowledge on downy mildew of grapevine and effective disease management // Phytopathologia Mediterranea. 2011. Vol. 50(1). P. 3-44.

8. Toffolatti S. L., Prandato M., Serrati L., Sierotzki H., Gisi U., Vercesi A. Evolution of Qol resistance in Plasmopara viticola oospores // European journal of plant pathology. 2011. V. 129(2). P. 331-338.

9. Santos R. F., Ciampi-Guillardi M., Fraaije B. A., de Oliveira A. A., Amorim L. The Climate-Driven Genetic Diversity Has a Higher Impact on the Population Structure of Plasmopara viticola Than the Production System or QoI Fungicide Sensitivity in Subtropical Brazil // Frontiers in microbiology. 2020. V. 11. P. 2236.

10. Kump I., Gessler C., Blaise P. Primary infections of Plasmopara viticola: should we revise our ideas about the quantitative relevance of oospores? // Bulletin OILB/SROP. 1998. Vol. 21(2). P. 9-11.

11. Stark-Urnau M., Seidel M., Kast W., Gemmrich A. Studies on the genetic diversity of primary and secondary infections of Plasmopara viticola using RAPD/PCR // Vitis. 2000. Vol. 39 (4). P. 163-166.

12. Delmotte F., Chen W. J., Richard-Cervera S., Greif C., Papura D., Giresse X., MondorGenson G., Corio-Costet M. F. Microsatellite DNA markers for Plasmopara viticola, the causal agent of downy mildew of grapes // Molecular Ecology Notes. 2006. Vol. 6 (2). P. 379-381.

13. Gobbin D., Pertot I., Gessler C. Identification of microsatellite markers for Plasmopara viticola and establishment of high throughput method for SSR analysis // European journal of plant pathology. 2003. Vol. 109 (2). P. 153-164.

14. Delmotte F., Machefer V., Giresse X., Rc S., Latorse M., Beffa R. Characterization of single-nucleotide-polymorphism markers for Plasmopara viticola, the causal agent of grapevine downy mildew // Applied and environmental microbiology. 2011. Vol. 77 (21). P. 7861-7863.

15. Rouxel M., Papura D., Nogueira M., Machefer V., Dezette D., Rc S., Carrere S., Mestre P., Delmotte F. Microsatellite markers for characterization of native and introduced populations of Plasmopara viticola, the causal agent of grapevine downy mildew // Applied and environmental microbiology. 2012. Vol. 78 (17). P. 6337-6340.

16. Arafa R., Kenta S. Technical review of molecular markers and next-generation sequencing technology to manage plant pathogenic oomycetes // African journal of biotechnology. 2018. Vol. 17 (12). P. 369-379.

17. Rogers S.O., Bendich A.J. Extraction of DNA from milligram amounts of fresh, herbarium and mummified plant tissues // Plant Molecular Biology. 1985. Vol. 5(2). P. 69-76.

18. Makarkina M.V., Il'nickaya E.T., Tokmakov S.V., Lobodina E.V. Aprobaciya DNK-markerov dlya izucheniya raznoobraziya patogena Plasmopara Viticola [Elektronnyj resurs] // Plodovodstvo i vinogradarstvo Yuga Rossii. 2019. № 60(6). S. 41-50. URL: http://journalkubansad.ru/pdf/19/06/05.pdf. DOI: 10.30679/2219-5335-2019-6-60-41-50 (data obrashcheniya: 14.01.2021).

19. Makarkina M. V., Tokmakov S. V., Ilnitskaya E. T. A study of the genetic polymorphism of Plasmopara viticola in the vineyards of the Krasnodar Territory // BIO Web of Conferences. II International scientific conference "plants and microbes: the future of bio-technology”. 2020. Vol. 23. P. 02005.

20. Gobbin D., Jermini M., Loskill B., Pertot I., Raynal M., Gessler C. Importance of secondary inoculum of Plasmopara viticola to epidemics of grapevine downy mildew // Plant Pathology. 2005. Vol. 54. P. 522-534. 